\title{
Correction to: 500-year tree-ring reconstruction of Salween River streamflow related to the history of water supply in Southeast Asia
}

\author{
Feng Chen ${ }^{1,2}\left(\mathbb{D} \cdot\right.$ Huaming Shang ${ }^{2} \cdot$ Irina Panyushkina ${ }^{3} \cdot$ David Meko $^{3} \cdot \mathrm{Jinbao}_{\mathrm{Li}}{ }^{4} \cdot$ Yujiang Yuan $^{2} \cdot$ Shulong Yu $^{2}$. \\ Fahu Chen ${ }^{5}$. Daming $\mathrm{He}^{1} \cdot$ Xian Luo $^{1}$
}

Published online: 18 September 2019

(c) Springer-Verlag GmbH Germany, part of Springer Nature 2019

\section{Correction to: Climate Dynamics \\ https://doi.org/10.1007/s00382-019-04948-1}

In the original publication of the article Fig. 1 was incorrect. The correct Fig. 1 is given below:

Amendments of Fig. 1 have been made to the non-scientific content of the article.

Publisher's Note Springer Nature remains neutral with regard tojurisdictional claims in published maps and institutional affiliations.

The original article can be found online at https://doi.org/10.1007/ s00382-019-04948-1.

Feng Chen

feng653@163.com

$\triangle$ Fahu Chen

fhchen@itpcas.ac.cn

1 Yunnan Key Laboratory of International Rivers and Transboundary Eco-Security, Institute of International Rivers and Eco-Security, Yunnan University, Kunming, China

2 Key Laboratory of Tree-ring Physical and Chemical Research of China Meteorological Administration/Xinjiang Laboratory of Tree-ring Ecology, Institute of Desert Meteorology, China Meteorological Administration, Urumqi, China

3 Laboratory of Tree-Ring Research, University of Arizona, Tucson, Arizona, USA

4 Department of Geography, University of Hong Kong, Hong Kong, China

5 Institute of Tibetan Plateau Research, Chinese Academy of Sciences (CAS), Beijing, China 


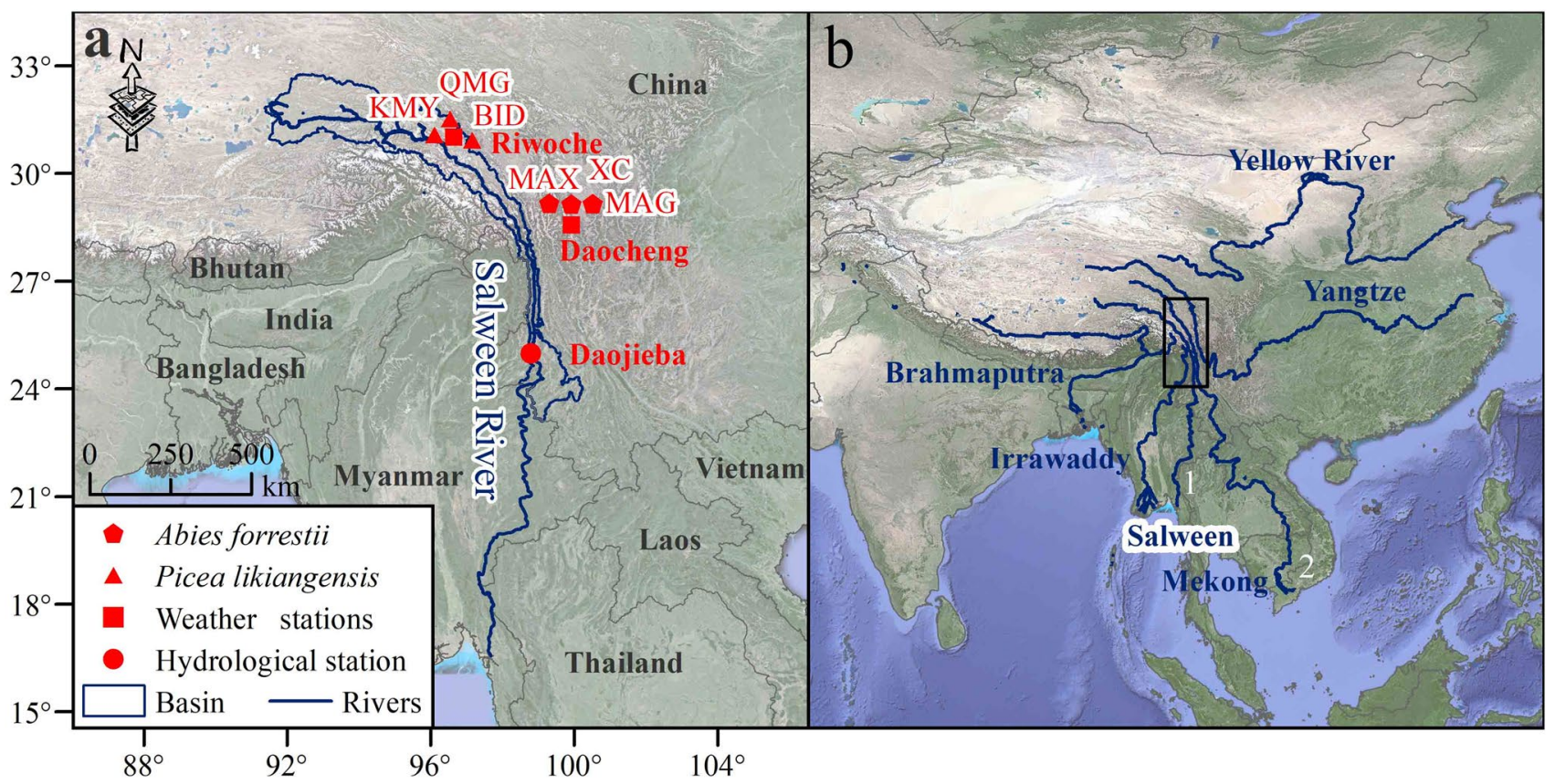

Fig. 1 Study region and data points. a Map of cross-border region of the Salween River Basin showing basin boundary and locations of the tree-ring sites, weather and hydrological stations. Table 1 lists the names of sites and stations. b Map of Southeast Asia showing major

rivers originating on the Tibetan Plateau. The numbers 1 and 2 denote the locations of MHS (Buckley et al. 2007) and BDNP (Buckley et al. 2010) sampling points 